\title{
A guide to the translation of the Global Initiative for Asthma (GINA) strategy into improved care
}

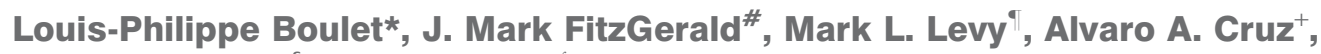 \\ Soren Pedersen ${ }^{\S}$, Tari Haahtela ${ }^{f}$ and Eric D. Bateman**
}

\begin{abstract}
In 1995, the Global Initiative for Asthma (GINA) published an evidence-based workshop report as a guide to clinicians managing asthma patients, and has updated it annually to ensure that recommendations remain current. Although the report has been widely disseminated and influenced clinical practice and research, its major objective, of forming the basis for local and national initiatives to improve services for asthma patients, remains to be achieved. Over recent years, the science of guideline implementation has progressed, and encouraging examples of successful asthma programmes have been published. This report is intended to draw on this experience and assist with the translation of asthma guideline recommendations into quality programmes for patients with asthma using current knowledge translation principles. It also provides examples of successful initiatives in various socioeconomic settings.
\end{abstract}

KEYWORDS: Asthma, education, Global Initiative for Asthma, implementation, knowledge translation, practice guidelines

W orldwide, significant "care gaps", defined as discrepancies between optimal and provided care, still exist for the management of major chronic diseases, including asthma and chronic obstructive pulmonary disease (COPD) [1, 2]. The provision of evidence-based guidelines has helped guide optimal disease management and clinical practice guidelines (CPGs) have been developed for most conditions $[3,4]$. Moreover, experience over two decades has also resulted in considerable modification and improvement in the methodology for their development. Quality standards have been suggested for the development of these guidelines, such as those stated in the AGREE (Appraisal of Guidelines for Research and Evaluation) tool and recent reports [5-8]. Furthermore, grading of the evidence has improved and tools such as the Grades of Recommendation, Assessment, Development and Evaluation (GRADE) system is being increasingly used by national and international societies, including the World Health Organization [9]. GRADE is considered by many as the best option to grade evidence in the production of current clinical practice guidelines, making it possible to bring the scientific evidence closer to real life and clinical practice. It provides a systematic and transparent framework that helps to clarify questions, determine the outcomes of interest, and summarise the evidence that addresses a question (GRADE working group, www.gradeworkinggroup.org).

However, even the best guidelines, if not adequately disseminated and implemented, will not influence patient care. It is obvious that, at best, the adoption and implementation of asthma guidelines is patchy. This is attributable to a large number of barriers, both at the programme level and due to the behaviour and habits of patients and physicians [1, 10-12]. As reviewed by BAIARDINI et al. [13], guidelines implementation is a complex process that is influenced by different factors, including the characteristics of guidelines, the social, organisational, economic and political context, and by implementation strategies. Patient's and physician's guideline implementation of recommendations are influenced by their knowledge, attitudes, skills, experiences, beliefs and values.

Fortunately, these issues have been considered and the science of guideline development has been

\section{AFFILIATIONS}

*Institut Universitaire de Cardiologie et de Pneumologie de Québec,

Quebec, QC

\#Institute for Heart and Lung Health, University of British Columbia,

Vancouver, BC, Canada.

-Primary Care Research and

Development, Division of Community Health Sciences, GP Section, University of Edinburgh, Edinburgh, UK.

+ProAR - Nucleo de Excelência em Asma of Federal, University of Bahia, Salvador, Brazil.

${ }^{\S}$ Paediatric Research Unit, University of Southern Denmark, Kolding Hospital, Kolding, Denmark.

${ }^{f}$ Skin and Allergy Hospital, Helsinki University Central Hospital, Helsinki, Finland.

**Division of Pulmonology, Dept of Medicine, University of Cape Town, Cape Town, South Africa.

CORRESPONDENCE

L-P. Boulet

Institut Universitaire de Cardiologie et de Pneumologie de Québec 2725 Chemin Sainte-Foy

Québec

G1V 4G5

QC

Canada

E-mail: Ipboulet@med.ulaval.ca

Received:

Oct 212011

Accepted after revision:

Dec 232011

First published online:

Jan 262012

European Respiratory Journal

Print ISSN 0903-1936

Online ISSN 1399-3003 
accompanied by the development of methodologies and tools to facilitate the uptake of guideline recommendations and to translate them into concrete actions. While these are better known to health systems experts, their importance is less well appreciated by practicing clinicians. Since narrowing the care gap involves both the organisation of health services and individual best practice, a co-ordinated, comprehensive and carefully planned approach is required, involving all players in the provision of healthcare [14-17]. Although lack of financial resources is often cited as the limitation to implementing improved care, the experience of many local and national initiatives is that quality improvements may be achieved with little or no additional financial cost (savings have even been reported) as cost shifting, principally from expenditure on acute services to effective chronic disease management, forms the basis of the strategy. Ideally, the quality improvement programme should involve dissemination of customised best practice guidelines, an implementation strategy and an evaluation plan to assess its impact and guide further programme improvements.

The need for these three components is not widely appreciated by those who, with good intentions, develop clinical practice guidelines. In a survey of 2,341 guideline developers who submitted their guidelines to the Canadian Medical Association Infobase between 1994 and 2005 (1,664 (71\%) surveys returned), although there had been improvements in guideline development methodology, developers were more likely to report using computerised search strategies (94\% versus $88 \%$ ), publish the search strategy ( $42 \%$ versus $34 \%$ ), reach consensus using open discussion (95\% versus $78 \%$ ), and evaluate the effectiveness of the dissemination strategies (12\% versus $6 \%$ ) for the periods 1994 1999 versus 2000-2005; dissemination and implementation activities appeared to have decreased, as had the study of the impact of the guidelines on health outcomes ( $24 \%$ versus $5 \%$ ) [18].

Guideline dissemination is the easiest of the three components, but may be the least effective. It is usually achieved through medical/scientific publications, mailings, continuing professional development, workshops, symposia and, increasingly, innovative internet-based programmes. Formal evaluation of the effectiveness of these methods confirms that some of the most widely practiced methods, such as lectures and distribution of guidelines, are ineffective or insufficient to change the behaviour of carers, particularly physicians. More complex interventions employing social marketing techniques are more successful, but form only part of successful strategies $[17,19]$.

Educational meetings alone do not seem to be effective in changing complex behaviour patterns amongst physicians [20]. GRIMSHAW et al. [21] reported a systematic review of the effectiveness and cost of different guidelines development, dissemination and implementation strategies. The authors concluded that there remains an imperfect evidence base as to which strategy is best, and that many factors need to be considered. For example, implementers should select a clinical need that is most likely to be responsive to an intervention, and has potential for improving behaviour. An assessment of barriers and facilitators of the intervention and its probable cost-benefit is essential. Readers are advised to consult some of the published literature on this topic [22-26].

Guideline implementation requires specific interventions tailored to different healthcare systems and settings, taking into account available human and material resources. Knowledge translation models have been developed to help "operationalise" the integration of evidence provided through guideline recommendations or other means of knowledge synthesis, e.g. Cochrane meta-analyses, web-based repositories and other forms of knowledge synthesis, into care, such as the "Knowledge-toAction" framework developed by GRAHAM et al. [27] (fig. 1). Furthermore, tools to assess "implementability" of a guideline (e.g. the GuideLine Implementability Appraisal (GLIA) tool) have become available and can be useful to evaluate how a particular guideline is translatable into care [28].

The purpose of this review is to provide some basic principles for practice guidelines implementation and outline the steps required, as well as examples of such initiatives in various socioeconomic settings. It is based on the current literature on CPG implementation and the experience of colleagues involved in the Global Initiative for Asthma (GINA). It is hoped that this will provide assistance to those considering local or national implementation of CPGs, particularly the GINA Strategy for Diagnosis and Management of Asthma.

\section{PLANNING A GUIDELINE IMPLEMENTATION PROGRAMME}

The steps involved in the development of a guideline implementation programme are shown in table 1. Although listed in the order in which they might be addressed, this can be amended according to local conditions. The programme described is for a national or regional initiative, but most steps need to be applied in smaller scale initiatives within practices, clinics and hospitals.

\section{Identify stakeholders and form a working group}

Stakeholders at national or local level should be identified and invited to participate, including public health authorities, government representatives, non-governmental organisations (NGOs), respiratory and allergy societies, patient organisations, etc. The motivation behind each participant's involvement should be determined to ensure that these are addressed and, as far as possible, met. Strategies should be considered to motivate other partners to become involved in the initiative.

Then, a working group should be developed. In some countries, this has been done under the auspices of, or in collaboration with, the national leadership of the Global Alliance against Chronic Respiratory Diseases [29], a scientific society, a group devoted to respiratory care or a local or national health authority. The intention should be, where possible, to ensure that the plan for asthma care is adopted by and becomes embedded in the activities of health services in a local region or national health authority. This is usually best achieved when health authorities become full members of the initiative and at an early stage of the process. The working group should include a mix of specialists / opinion leaders in the management of asthma, primary care physicians and general practitioners, nurses, pharmacists, health educators and patients with asthma. Ideally, specialists in implementation methodology and communications should also be involved. It should be remembered that enduring and productive collaborations are more likely when partners are involved from the start, rather than when they are invited later.

Once an implementation plan has been developed participants should agree on milestones, and then allocate specific tasks to 


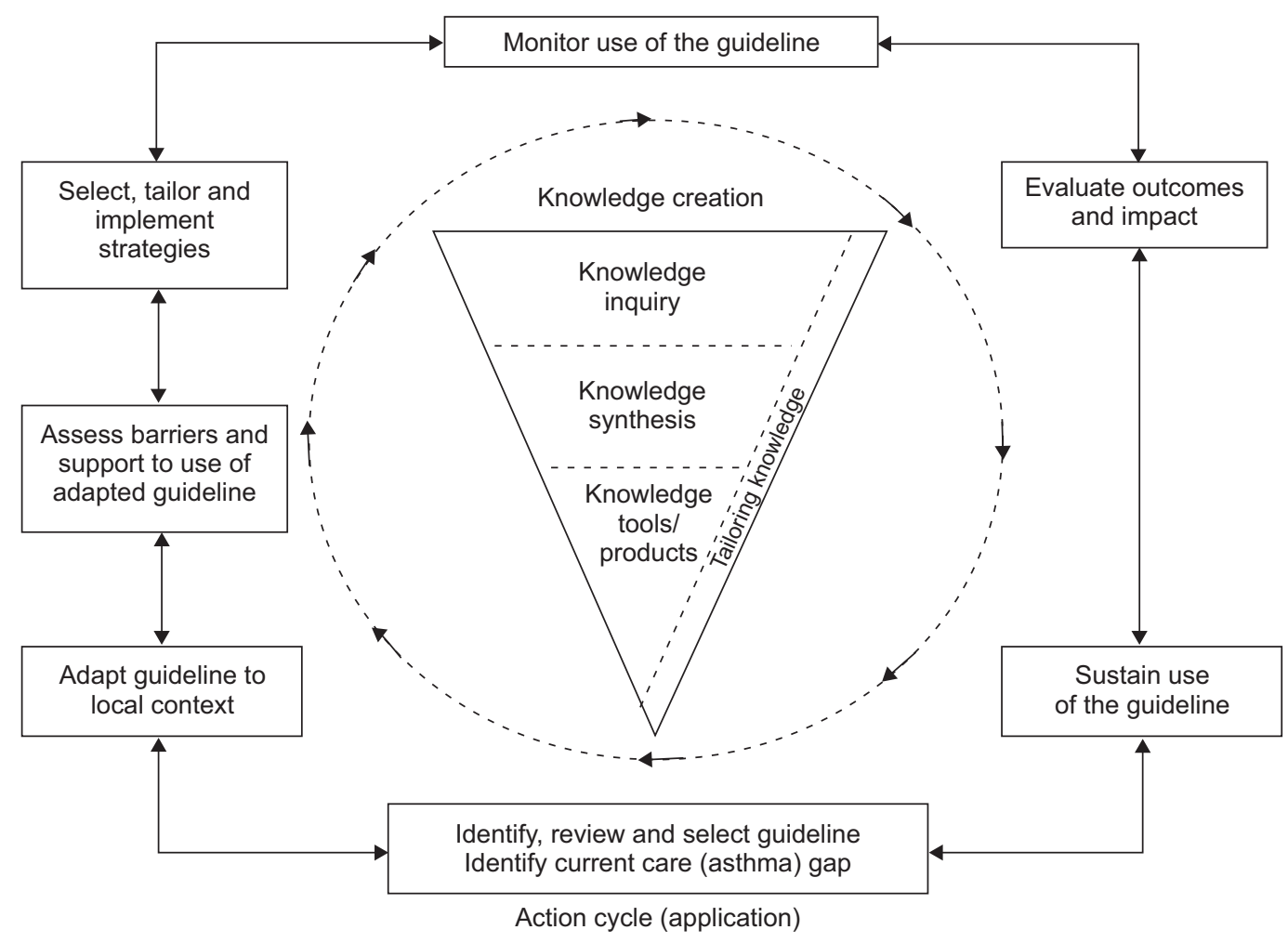

FIGURE 1. The "Knowledge-to-Action" framework. Adapted from [27].

members to ensure that the work is completed within a realistic timeframe. It is usually best to develop the plan around existing structures and interested groups. Ideally a project co-ordinator should be hired to supervise the various aspects of the initiative.

\section{Select the guideline to be implemented and whether it requires adaptation}

Before disseminating or attempting to implement guidelines they must be adapted for use in the intended practice setting. This

\section{TABLE 1 A plan for a guideline implementation programme}

1. Identify stakeholders and form a working group

2. Select the guideline to be implemented and determine whether it needs adaptation

3. Perform a needs assessment and review current status of care and main care gaps

4. Select the main care gaps to be addressed and key messages to convey

5. Develop and prioritise implementation strategies

6. Develop and agree on specific indicators of change and targets for each outcome in the initiative

7. Ensure that the resources required are available

8. Produce a step-by-step implementation plan

9. Plan initial interventions and evaluate their effects

10. Review the project in light of pilot projects and other information gathered

11. Determine how the current interventions could be improved/evaluate the feasibility of implementing the project

12. Plan continuation/expansion of the initiative and its long-term evaluation: ensure long-term planning should be done by local experts, but more sophisticated instruments, such as ADAPTE [30], have been developed in recent years to provide a framework for this task. This method involves a series of steps, including: 1) the planning and set-up; 2) the adaptation process; and 3) the development of a final document. Although this require resources and expertise, in many instances it serves as a valuable exercise to sensitise the team to local realities and results in a more implementable management and treatment guideline.

\section{Perform a needs assessment and review of current status of care and main care gaps}

The most up-to-date statistics on asthma morbidity, mortality and healthcare use in the target area, including hospital admissions, should be collected. The most useful of these are statistics on hospitalisations and emergency room visits for asthma, as proposed in the recently launched GINA 5-Year Asthma Control Challenge [31].

Next to consider is whether there is a comprehensive review of current practices and resources available for the care of patients with asthma. This should involve points of care (public and private sector), referral patterns (including use of acute care facilities and hospitals), availability and accessibility of asthma drugs, organisation of health services, training of health carers and practitioners, treatment policies and practices, and many other facts.

This analysis will enable the identification of barriers of implementation. Barriers to optimal care, [32, 33], include external barriers that limit the ability to perform the recommended action, such as those related to patients, guidelines or 
environmental factors, and internal barriers that limit adherence. The latter include prevailing knowledge gaps, beliefs and attitudes. Barriers relating to both caregivers and to patients should be considered.

\section{Select the main care gaps to be addressed and key messages to convey}

A list of common asthma management care gaps is shown in table 2. Care gaps should be ranked in terms of the size and their effect upon the morbidity and/or mortality. The reasons for gaps should be sought and considered in planning strategies for addressing them. Finally, the strategy for educating carers and patients must be developed. The most important gaps must be prioritised and a limited number (three or four) selected for social marketing. Social marketing is defined as the systematic application of marketing to achieve specific behavioural goals for social good. The messages must be few, simple, clear and practical. The language and emphasis must be tailored to the group to whom they are addressed. For example, for health professionals a message might be that: "a child that coughs at night in the absence of a cold may have asthma"; "inhaled corticosteroid is the treatment of choice for persons with persistent asthma symptoms"; and "persistent symptoms of bronchitis after an upper respiratory tract infection indicates a need for intensified controller treatment for asthma". For patients and parents, "asthma attacks do not routinely require antibiotics".

\section{Develop and prioritise implementation strategies}

A review of experience in other countries or practice environments similar to that being considered will provide useful clues

\section{TABLE 2 Common asthma management care gaps ${ }^{\#}$}

\begin{tabular}{|c|c|c|c|}
\hline Management care gap & $\begin{array}{c}\text { Example of barriers to reduce } \\
\text { the gap }\end{array}$ & $\begin{array}{l}\text { Possible implementation } \\
\text { strategy }\end{array}$ & $\begin{array}{l}\text { Process and outcome } \\
\text { measures }\end{array}$ \\
\hline $\begin{array}{l}\text { Over/underdiagnosis/lack of early } \\
\text { recognition of asthma }\end{array}$ & $\begin{array}{l}\text { Unavailability of pulmonary } \\
\text { function tests }\end{array}$ & $\begin{array}{l}\text { Identification of nearby pulmonary } \\
\text { function test facilities }\end{array}$ & $\begin{array}{l}\text { Percentage of patients in } \\
\text { whom pulmonary function } \\
\text { tests are performed }\end{array}$ \\
\hline $\begin{array}{l}\text { Not considering asthma when symptoms } \\
\text { present }\end{array}$ & Increase awareness & Increase awareness & $\begin{array}{c}\text { Prevalence of new asthma } \\
\text { diagnoses }\end{array}$ \\
\hline Physician's non-adherence to guidelines & $\begin{array}{l}\text { Insufficient knowledge/motivation } \\
\text { to implement guideline }\end{array}$ & $\begin{array}{l}\text { Improved dissemination/ } \\
\text { interactive workshops }\end{array}$ & $\begin{array}{c}\text { Assessment of recommendations } \\
\text { implementation into care }\end{array}$ \\
\hline Patient-doctor communication & $\begin{array}{l}\text { Insufficient time/communication } \\
\text { skills }\end{array}$ & $\begin{array}{l}\text { System changes: asthma } \\
\text { educator referral }\end{array}$ & $\begin{array}{l}\text { Degree of patient satisfaction } \\
\text { with communication }\end{array}$ \\
\hline Inadequate assessment of asthma control & Lack of knowledge of criteria & Education/CME & Survey of criteria use \\
\hline $\begin{array}{l}\text { Insufficient environmental/ } \\
\text { preventative measures }\end{array}$ & Lack of time to explain & $\begin{array}{l}\text { Increase access to educator } \\
\text { Involve patients as educators }\end{array}$ & $\begin{array}{l}\text { Survey implementation of } \\
\text { intervention }\end{array}$ \\
\hline $\begin{array}{l}\text { Lack of individualised } \\
\text { pharmacotherapy }\end{array}$ & $\begin{array}{l}\text { Insufficient knowledge } \\
\text { of guideline }\end{array}$ & Education/CME & $\begin{array}{l}\text { Assessment of treatment } \\
\text { (e.g. audit) }\end{array}$ \\
\hline $\begin{array}{l}\text { Lack of education and guided } \\
\text { self-management }\end{array}$ & Unavailability of educators & $\begin{array}{l}\text { Increase access to educator } \\
\text { Involve patients as educators } \\
\text { in the process }\end{array}$ & $\begin{array}{l}\text { Percentage of patients offered } \\
\text { education }\end{array}$ \\
\hline $\begin{array}{l}\text { Absence or no use of an action plan } \\
\text { for the management of exacerbations }\end{array}$ & $\begin{array}{l}\text { Not enough time to produce } \\
\text { and explain }\end{array}$ & $\begin{array}{l}\text { Increase access to educator, involve } \\
\text { patients as educators in the process } \\
\text { Provide simple printed formats } \\
\text { for clinicians }\end{array}$ & $\begin{array}{l}\text { Number of patients receiving } \\
\text { a written } \\
\text { action plan }\end{array}$ \\
\hline $\begin{array}{l}\text { No assessment of techniques (inhalers, } \\
\text { peak flow measurement) }\end{array}$ & Lack of time or knowledge & Systematic assessment at visits & $\begin{array}{l}\text { Percentage of patients in whom } \\
\text { this is checked }\end{array}$ \\
\hline No assessment of adherence to therapy & Not integrated to practice & Reminders & $\begin{array}{l}\text { Percentage of patients in whom } \\
\text { this is checked }\end{array}$ \\
\hline No regular follow-up: discontinuity of care & Lack of follow-up arrangements & Improved management & Survey on regular follow-up \\
\hline Inadequate management of acute asthma & Inadequate management & $\begin{array}{c}\text { Adherence to guidelines Improve ED staff } \\
\text { training/asthma management }\end{array}$ & $\begin{array}{l}\text { Regular survey of hospital } \\
\text { admissions and deaths }\end{array}$ \\
\hline $\begin{array}{l}\text { Variable/insufficient access to care: non- } \\
\text { availability of asthma controllers }\end{array}$ & Insufficient resources & Increase resources: revise process & Assess continuity of care \\
\hline $\begin{array}{l}\text { Poor communication between various } \\
\text { groups of health care personnel }\end{array}$ & Lack of willingness to change & $\begin{array}{l}\text { Organise joint sessions on } \\
\text { asthma care }\end{array}$ & $\begin{array}{l}\text { Focus group assessing this } \\
\text { aspect of care }\end{array}$ \\
\hline
\end{tabular}

CME: continuing medical education; ED: emergency department. ${ }^{\#}$ : for some of these care gaps, more evidence on the effectiveness of implementation strategies is required; however, the recommendations provided are based on current recommendations. 
to successful interventions and approaches. Examples of these are provided as resources on the GINA website (www.ginasthma. org).

Prioritisation of strategies could be based on their ability to address identified barriers and to leverage identified facilitators in a specific context. Evaluating the evidence about the effectiveness of the strategy is also important. The Cochrane Effective Practice and Organization of Care Group (EPOC) publications are a useful reference for checking the effectiveness of proposed interventions [34]. It should be remembered that quality of care improvements are generally made in small steps that address critical barriers rather than through broad-ranging changes.

For example, all of the following have been shown to improve asthma outcomes: increasing access to controller drugs (inhaled corticosteroids); encouraging the performance of spirometry; improving the recognition and diagnosis of asthma; increasing awareness of the need to assess asthma control; encouraging use of written action plans; and providing asthma education [35-39]. It is wise for the working group to first select interventions that it considers will have the greatest societal impact, such as improving access to inhaled corticosteroids in children, especially those with a recent hospital admission [40], as this serves as encouragement to all involved and is likely to attract the attention of health authorities.

Finally, patients "at risk" should be targeted. These include patients with frequent exacerbations and/or highest morbidity, those with poor adherence to treatment and follow-up, and those with psychosocial and economic problems [41]. Teenagers and elderly patients are also "at-risk" groups [42, 43].

Among the most effective methods are: reminders, ideally at the site of care; interactive workshops; audit and feedback; and multifaceted interventions combining two or more methods, such as audit and feedback, reminders, local consensus processes or social marketing [38, 44-46].

\section{Develop and agree on specific indicators of change and targets for each outcome in the initiative}

Medical audit has been used to improve both the process and the quality of care for patients. The process involves setting standards, measuring current care against those standards, identifying gaps between the standards and the achievement of these, and finally, following up the performance of new interventions in terms of these standards. This process serves both as a stimulus to change and as a means of educating health professionals on best guideline-based practice [21, 37, 47-49]. Live, dynamic audit can be used to provide data, with immediate feedback for participants, as a motivator for change. In one such example (available at www.guideline-audit.com), physicians audited their care of patients with COPD and chest infections, and the diagnosis, acute management and assessment of control of patients with asthma and were able to compare their management performance with that of others and standard benchmarks.

An integral part of guideline implementation is the selection of realistic targets and key indicators to determine if these have been achieved. Ideally, a main goal and a selection of secondary objectives should be identified. The most relevant outcomes to be measured and what levels of change should be achieved should be decided (table 3). Furthermore, milestones for evaluating the

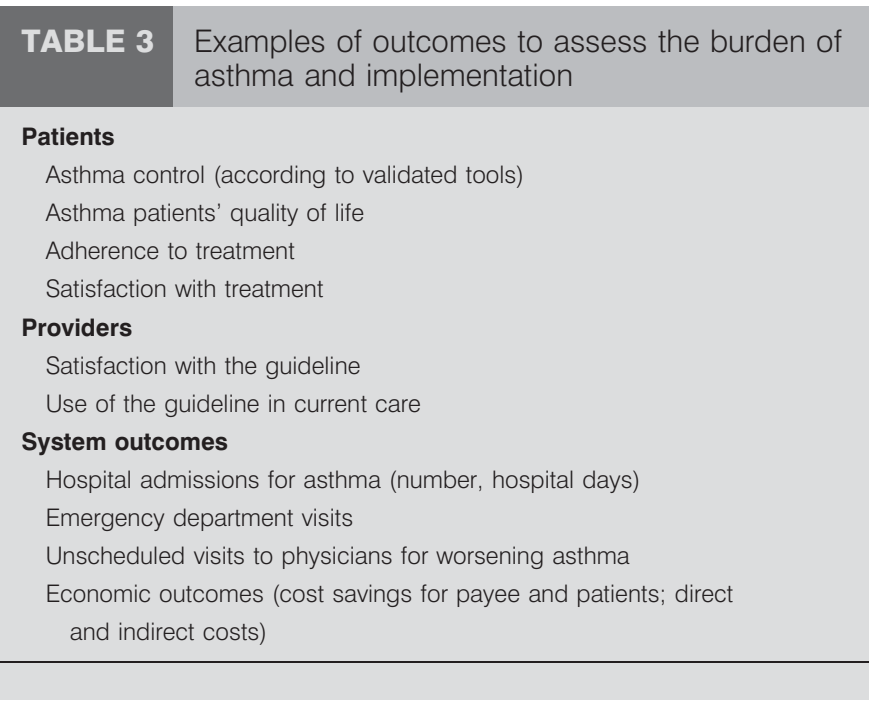

interventions should be established with specific proposals for the type of action to be considered if the targets are not achieved.

\section{Ensure that the resources required are available}

It is essential to determine the resources and funding that will be required to support the initiative, and to assess whether they are available. Funding can be obtained from various sources, including national funds, funding agencies (for implementation research), medical or scientific societies, and industry partners.

\section{Produce a step-by-step implementation plan}

The implementation plan should involve an initial intervention or a series of pilot projects that provide the basis for the final plan and its expansion and scale-up in the target region. Long-term sustainability must be a primary objective of any plan.

It is usually wise to begin on a small scale with a limited number of people, and select an initial intervention that has a good chance of success, as this will motivate the group. It is also important to initially select a targeted group who express interest in seeing the plan implemented. The importance of buy-in was illustrated by SHEEHAN [50] who reported that while only $53 \%$ of those stating their intention to implement an action did so, in those expressing reluctance only, 3\% became involved. Furthermore, choosing a medium-range time schedule (e.g. 3 months) will allow rapid assessment of early results. The initiative should then be reviewed in light of the initial pilot projects and other information gathered to determine whether and how the strategy should be continued or improved, and if it is sustainable with the current available resources and level of commitment from the planning group and other parties.

The outcome of interventions should be assessed according to the pre-determined indicators, and barriers and facilitators should be reviewed on a regular basis. The monitoring/evaluation processes must capture unintended outcomes or impacts, as well as expected ones (or ones of interest). Other aspects of the project, such as cost-benefit, reduction of morbidity outcomes, healthcare use, etc. (table 3), are important in making decisions on long-term goals and refinement of strategies. Successes should be publicised; a useful format is to describe successes around individual cases and personal experiences. 


\section{Ensure long-term planning}

Continuation and expansion of the initiative and its long-term evaluation process should then be decided. It should be determined how the intervention will be sustained, who will be charged with the task of ensuring its continuation, and how continuing financial and organisational support will be provided. Regular communications on the project's impact on current care will help to sustain interest and provision of resources for the project.

\section{USE OF KNOWLEDGE TRANSLATION THEORIES IN DEVELOPING IMPLEMENTATION PLANS}

Knowledge translation initiatives should be based on sound behavioural and educational theories and evidence-based strategies, such as those described in the Cochrane EPOC Group [34]. A more recent model developed in Canada is the Knowledge-toAction conceptual framework developed by GRAHAM et al. [27], which builds upon commonalities found in an assessment of planned action theories (fig. 1). The Knowledge-to-Action framework involves three phases.

In the planning phase, selected guideline recommendations are prioritised. Once the targeted population and settings have been selected, the key messages and main outcomes of measurement to evaluate how implementation is successful are decided, as well as the actions to be taken.

In the assessment phase, current status of implementation and uptake by the target audience are evaluated, as well as the impact of the intervention and its sustainability of the implementation intervention. The intervention should be tailored, and the strategy selected according to the targeted population; it should identify potential barriers to implementation.

Finally, uptake by the targeted population and selected outcomes should be monitored for impact and sustainability. The action cycle allows interventions to be improved upon by building on successes and learning from failures, in addition to reassessing and addressing barriers and facilitator's overtime. The impact of the intervention should, therefore, be adequately evaluated at the patient, provider and system levels.

\section{NEW METHODS OF GUIDELINE DISSEMINATION IN SUPPORT OF IMPLEMENTATION PLANS}

New communication tools, such as the Internet, smartphones and hand-held computers, offer innovative ways of communicating guideline recommendations [51]. Web-based programmes, social networking and other means of interacting (e.g. communities of practice) are being increasingly used for guidelines dissemination and translation [52,53]. Embedding guidelines into electronic health records is a novel way of improving access to treatment recommendations at the site of care [24]. Further research is required to determine the effectiveness of these methods.

STRATEGY PROPOSED WITHIN THE CONTEXT OF GINA One of the major goals of GINA is to disseminate proven methodologies for implementing asthma guidelines and, in particular, the GINA Global Strategy for Asthma Management and Prevention report [54]. Those interested in being more aligned with this goal may wish to consider becoming a GINA country initiator. A GINA country initiator is a person or an organisation that is prepared to initiate the process of forming a national or local task team. The initiator is given the endorsement of the GINA Dissemination and Implementation Committee and becomes a member of the GINA Assembly. This position ensures that the initiator receives encouragement from GINA and has the opportunity to present their programme and progress to GINA for comment and advice.

Potential partners in GINA strategy implementation initiatives could be identified within a ministry of health, such as: programme managers and technical staff from specific programmes on chronic respiratory diseases; programme managers and technical staff from supporting programmes, services, and departments such as the human resources development department, the health statistics department, the health finance department, the drug control department, the health education programme, the health care reforms unit, and the environmental health unit. They may also be from outside the ministry of health, for example: related ministries (education, science and technology, social welfare, sport and leisure, labour, industry and environment); chronic respiratory diseases experts; knowledge translation experts; public health experts from academic and training faculties; representatives from professional associations, scientific societies (medical, pharmacists, physiotherapists and nursing) and patient groups; local and international NGOs; representatives from the educational sector; potential partners who provide technical and financial support, such as multilateral and bilateral agencies; and representatives from the community, churches and religious leaders, the private sector and the media.

\section{EXAMPLES OF SUCCESSFUL ASTHMA GUIDELINE IMPLEMENTATION INITIATIVES}

The examples provided below illustrate the processes described above, and in particular the various stages of the Knowledge-toAction framework (fig. 1).

\section{Finland}

A multidisciplinary national asthma programme included strategies for prevention and treatment, but also an operational plan for their dissemination and implementation [54-59]. Effective strategies involve multiple methods, decision support systems and interactive education. In Finland, state officials, representatives of patient organisations, nurses, pharmacists and general practitioners took part in the steering group of the programme. They created a network of asthma responsible contact persons in local health centres, as well as regional treatment action plans. This network included as many nurses as doctors but also pharmacists in almost every pharmacy in Finland. The contact persons coordinated the local work, but did not personally take care of all asthmatics. The network was kept motivated by continuous educational activities, which had a high rate of participation. The organisational key to success was to emphasise the role of general practitioners in addition to specialist care.

The asthma-specific key for treatment improvement was the strong message to detect asthma early and start anti-inflammatory medication immediately after diagnosis, i.e. "hit early and hit hard". The idea was to take control of asthma by using a stepdown rather than a step-up strategy. Once control was achieved, the minimum medication to maintain control was titrated during 3-6 months. To prevent asthma attacks and worsening asthma, especially during respiratory infections, guided self-management was effectively implemented. The patient was taught by the general practitioner or nurse to increase the inhaled medication 
instantly if signs of symptom increase appeared. The patients also had corticosteroid tablets at home and instructions on how to start the course themselves if intensified inhalation therapy did not improve control within a few days.

The extra costs of planning and implementing the programme were small, mainly as most of the activities were carried out as part of the routine work of the clinicians and administrators. From 1994 to 2000 the number of asthma medication users for persistent disease in Finland increased by $42 \%$, and detection and treatment of asthmatic symptoms in the population improved. The major increase $(75 \%)$ in the use of inhaled corticosteroids was a direct consequence of the programme which promoted their introduction as first-line therapy. The savings of total asthma costs (hospital days, out-patient visits, medication, disability and loss of production) were significant, from $€ 300$ million to almost $€ 500$ million (minimum or maximum scenario) in one year, 2005 [60].

\section{Brazil}

Many programmes have been developed in Brazilian cities in the last decade [61-64]. The Program for Control of Asthma (ProAR) was developed in 2003 in Salvador, prioritising the control of severe asthma. By facilitating referrals from the public health system and providing proper multidisciplinary, but simple, management including education and medication for free, ProAR enrolled $>4,000$ patients with severe asthma in four reference clinics. The patients are offered regular follow-up and discharged back to primary healthcare only when asthma control can be maintained without requirement of a combination of an inhaled corticosteroid and a long-acting $\beta_{2}$-agonist. This intervention was associated with a steep decline in health resource utilisation and remarkably reduced the rate of hospital admissions due to asthma in the entire 2.8 million city habitants by $74 \%$ in 3 yrs [59]. Cost analysis demonstrated that this intervention was very cost-effective and provided a financial relief to the families and the government [62,63]. Various other programmes have been developed in large Brazilian cities or smaller towns with favourable results, such as the intervention reported in Itabira [64].

\section{South Africa}

In South Africa, the management of asthma and other chronic diseases in the public health sector has, to some extent, been eclipsed by the demands of treating large numbers of patients with tuberculosis and HIV infection. Researchers in South Africa have developed and, over the course of several years, achieved the nationwide rollout of a programme that includes asthma in the component of comprehensive primary care offered for all common respiratory diseases, including COPD, tuberculosis and other infections. This programme is based on the Practical Approach to Lung Health (PAL), developed by the World Health Organization. PALSA Plus, as it is termed in South Africa, is a locally customised, integrated, algorithm-based diagnostic and management tool for use by nurses and front-line doctors in primary care clinics. It has improved the recognition of and ensured resourcing for the management of asthma in these facilities. The intervention comprises a practical high-quality manual (guideline) containing details of diagnosis and management of asthma (updated annually) and educational aids developed using latest knowledge translation methodology. Educational outreach is performed using social marketing techniques and audit forms a part of the programme. To date,
$>13,000$ nurses have received training in the methods and initial results from field research confirm improvements in care, including increased prescriptions of inhaled corticosteroids [65, 66]. The impact of this programme on mortality and hospitalisations remains to be confirmed.

\section{Ireland}

Irish asthma guidelines published in 2000 were based on the GINA international asthma management strategy [67]. In a survey of 400 patients with current asthma over the previous year, $27 \%$ reported having had either an emergency visit to the hospital or their general practitioner, $7 \%$ had been hospitalised for asthma, 19\% had sleep disturbance at least once a week, and $29 \%$ missed work or school. The level of asthma control and asthma management in Ireland still falls short of recommended national and international asthma guidelines and initiatives to address this problem have been developed with the full support of the national department of health.

\section{Canada}

The impact of asthma guidelines not only on asthma care but also broader policy issues has been reviewed [68]. There are emerging models of improved management of chronic disease with targeted funding to improve physicians adherence to guidelinebased care. In British Columbia, the number of hospitalisations for acute asthma has fallen from $>3,000$ annually to $<1,000$ between 2003 and 2007 (H. Platts, Ministry of Health, British Columbia, Canada; personal communication). In addition, in the context of multicultural societies, the impact of health literacy and ethnicity has been emphasised [69].

In the province of Quebec, Towards Excellence in Asthma Management (TEAM) was a four-phase disease management programme of the Quebec Asthma Education Network (QAEN) to be carried out over an 8-yr period [70]. It included: 1) the determination of current asthma-associated morbidity and mortality in various Quebec regions using population maps; 2) analysis of the burden of asthma, taking into account the socioeconomic consequences of the disease and the quality of life of the patients; 3) comparing current medical practices with the Canadian Asthma Consensus Guidelines for adult and paediatric populations; and 4) determining patient's adherence with medical treatment and with the environmental change recommendations. Key observations from this programme included: the identification of specific patterns of non-adherence in the use of inhaled corticosteroids; a lack of progress in increasing access to spirometry in asthma education centres in order to detect new cases; an increase in the number of referrals to an asthma educator; improvement in the ability of nurses to provide asthma education using an asthma hotline telephone service; and the beneficial effects of practice tools aimed at facilitating the assessment of asthma control and treatment needs by general practitioners. This programme has informed continuing efforts to improve guideline implementation.

\section{Other countries}

In a review of efforts to implement asthma guidelines in developing countries, AїT-KHALED et al. [71] evaluated 456 consecutive patients from Algeria, Guinea, Ivory Coast, Kenya, Mali, Morocco, Syria, Turkey and Vietnam. Overall, in 58\% of patients surveyed, the diagnosis of asthma had been confirmed 


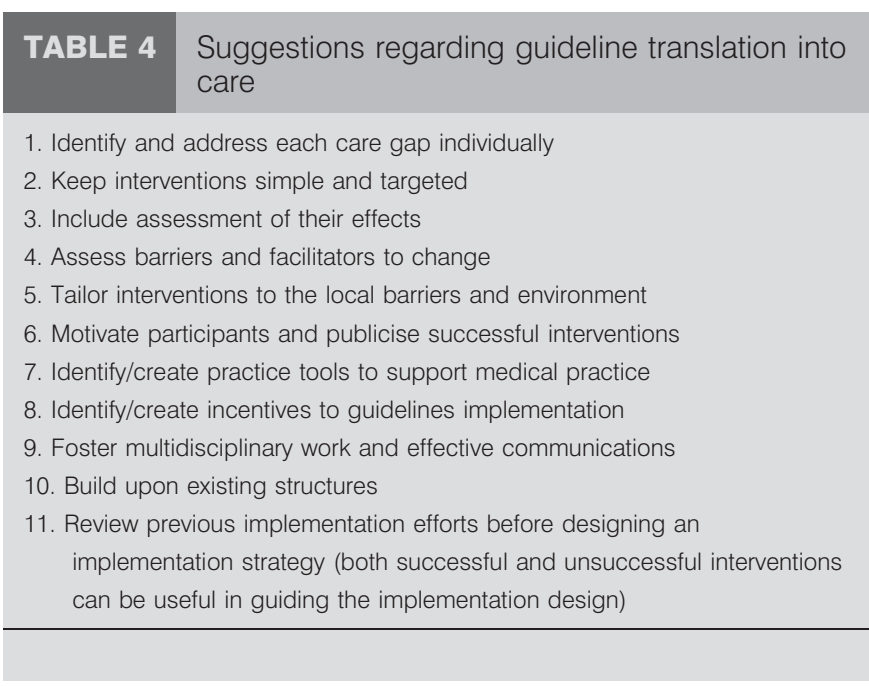

using recognised criteria. Agreement between the practitioner and the guidelines in assigning a grade of severity was moderate. Practitioners tended to underestimate the severity of asthma. Agreement between the practitioners' assessment of severity and treatment with inhaled corticosteroids was poor and inhaled corticosteroids were underutilised.

\section{THE FUTURE OF GUIDELINES IMPLEMENTATION}

Much remains to be done with regard to guidelines implementation. The basic principles of guideline implementation are well established, but unfortunately, resources continue to be wasted on ineffective methods $[16,17,19]$ (table 4$)$. It is important that both effective and ineffective attempts to implement asthma guidelines be reported so that others can learn from these experiences. Joint international efforts, for example through the Guidelines International Network, provide a forum for guideline implementers to exchange ideas on effective methods for overcoming barriers to knowledge translation, and access tools to produce better and more "translatable" guidelines. It is probable that new means of communication, such as computerbased programmes or exchanges through the Internet, will be used [72].

\section{CONCLUSIONS}

Evidence-based guidelines are intended to provide best practice advice, but the science of implementing them has lagged behind. Knowledge translation techniques have been developed and there are encouraging examples of their use in several countries. Although conditions may vary in different practice settings, a common set of principles for successful guideline adaptation and implementation are now available, are gaining wider use and their effectiveness has been confirmed, even in resource-poor settings. Given the continued increase in asthma prevalence in most countries and the continuing care gaps identified in almost all, GINA, together with other members of the medical community involved in asthma care, should see implementation as the most urgent priority if progress is to be made in addressing this treatable condition.

\section{SUPPORT STATEMENT}

This overview was supported by the Global Initiative for Asthma.

\section{STATEMENT OF INTEREST}

Statements of interest for all authors can be found at www.erj. ersjournals.com/site/misc/statements.xhtml

\section{ACKNOWLEDGEMENTS}

We sincerely thank I.D. Graham (University of Ottawa, Ottawa, ON, Canada) and S. Gupta (University of Toronto, Toronto, ON, Canada) for their most useful comments on this manuscript, and S. Carette (Institut Universitaire de Cardiologie et de Pneumologie de Québec, Quebec, QC, Canada) for her secretarial help.

\section{REFERENCES}

1 Boulet LP, Becker A, Bowie D, et al. Implementing practice guidelines: a workshop on guidelines dissemination and implementation with a focus on asthma and COPD. Can Respir J 2006; 13: 5-47.

2 Lalloo UG, McIvor RA. Management of chronic asthma in adults in diverse regions of the world. Int J Tuberc Lung Dis 2006; 10: 474-483.

3 Burgers J, Grol R, Eccles M. Clinical guidelines as a tool for implementing change in patient care. In: Grol R, Wensing $\mathrm{M}$, Eccles M, eds. Improving Patient Care. The Implementation of Change in Clinical Practice. Oxford, Butterworth-Heinemann, 2005; pp. 71-92.

4 Woolf SH, Grol R, Hutchinson A, et al. Clinical guidelines: potential benefits, limitations, and harms of clinical guidelines. BMJ 1999; 318: 527-530.

5 The AGREE Collaboration. Development and validation of an international appraisal instrument for assessing the quality of clinical practice guidelines: the AGREE project. Qual Saf Health Care 2003; 12: 18-23.

6 Brouwers MC, Kho ME, Browman GP, et al. AGREE II: advancing guideline development, reporting and evaluation in health care. CMAJ 2010; 182: E839-E842.

7 Brouwers MC, Kho ME, Browman GP, et al. Development of the AGREE II, part 1: performance, usefulness and areas for improvement. CMAJ 2010; 182: 1045-1052.

8 Brouwers MC, Kho ME, Browman GP, et al. Development of the AGREE II, part 2: assessment of validity of items and tools to support application. CMAJ 2010; 182: E472-E478.

9 Guyatt GH, Oxman AD, Schünemann HJ, et al. GRADE guidelines: a new series of articles in the Journal of Clinical Epidemiology. J Clin Epidemiol 2011; 64: 380-382.

10 Partridge MR. Translating research into practice: how are guidelines implemented? Eur Respir J 2003; 21: Suppl. 39, 23s-29s.

11 FitzGerald JM, Boulet LP, McIvor RA, et al. Asthma control in Canada remains suboptimal: the Reality of Asthma Control (TRAC) study. Can Respir J 2006; 13: 253-259.

12 Harrison MB, Légaré F, Graham ID, et al. Adapting clinical practice guidelines to local context and assessing barriers to their use. CMAJ 2010; 182: E78-E84.

13 Baiardini I, Braido F, Bonini M, et al. Why do doctors and patients not follow guidelines? Curr Opin Allergy Clin Immunol 2009; 9: 228-233.

14 Davis DA, Taylor-Vaisey A. Translating guidelines into practice: a systematic review of theoretic concepts, practical experience and research evidence in the adoption of clinical guidelines. CMAJ 1997; 57: 408-416.

15 Kitson AL, Strauss S. Identifying the knowledge-to-action gaps. In: Straus S, Tetroe J, Graham I, eds. Knowledge Translation in Health Care: Moving from Evidence to Practice. Oxford, Wiley-Blackwell Publishing, 2009.

16 Grol R. Effective organization of the implementation. In: Grol R, Wensing $\mathrm{M}$, Eccles $\mathrm{M}$, eds. Improving Patient Care. The implementation of change in clinical practice. Oxford, Elsevier, 2005; pp. 208-219. 
17 Grol R, Grimshaw J. From best evidence to best practice: effective implementation of change in patients' care. Lancet 2003; 362: 1225-1230.

18 Kryworuchko J, Stacey D, Bai N, et al. Twelve years of clinical practice guideline development, dissemination and evaluation in Canada (1994 to 2005). Implement Sci 2009; 4: 49.

19 Gibson PG. Implementing evidence-based guidelines. Med J Aust 2001; 174: 377-378.

20 Forsetlund L, Bjørndal A, Rashidian A, et al. Continuing education meetings and workshops: effects on professional practice and health care outcomes. Cochrane Database Syst Rev 2009; 2: CD003030.

21 Grimshaw JM, Thomas RE, MacLennan G, et al. Effectiveness and efficiency of guideline dissemination and implementation strategies. Health Technol Assess 2004; 8: 1-72.

22 Wensing M, Bosch M, Grol R. Selecting, tailoring and implementing knowledge translation. In: Straus S, Tetroe J, Graham ID, eds. Knowledge Translation in Health care: Moving from Evidence to Practice. Oxford, Wiley-Blackwell, 2009; pp. 94-112.

23 Gross PA, Greenfield S, Cretin S, et al. Optimal methods for guideline implementation: conclusions from Leeds Castle meeting. Med Care 2001; 8: II85-II92.

24 Registered Nurses Association of Ontario. Toolkit: Implementation of clinical practice guidelines. Toronto, Canada, 2002.

25 Wensing M, Van der Weijden T, Grol R. Implementing guidelines and innovations in general practice: which interventions are effective? Br J Gen Pract 1998; 48: 991-997.

26 Bhattacharyya O, Zwarenstein M. Methodologies to evaluate effectiveness of knowledge translation interventions. In: Straus S, Tetroe J, Graham ID, eds. Knowledge Translation in Health Care: Moving from Evidence to Practice. Oxford, Wiley-Blackwell, 2009; pp. 249-260.

27 Graham ID, Logan J, Harrison MB, et al. Lost in knowledge translation: time for a map? J Contin Educ Health Prof 2006; 26: 13-24.

28 Shiffman RN, Dixon J, Brandt C, et al. The Guideline Implementability Appraisal (GLIA): development of an instrument to identify obstacles to guideline implementation. BMC Med Inform Decis Mak 2005; 5: 23.

29 Bousquet J, Dahl R, Khaltaev N. Global alliance against chronic respiratory diseases. Allergy 2007; 62: 216-223.

30 ADAPTE Collaboration. ADAPTE Framework. www.adapte.org/ www/ Date last accessed: February 23, 2012.

31 Global Initiative for Asthma. www.core.ubc.ca/asthma/gina Date last accessed: February 23, 2012.

32 Cabana MD, Rand CS, Powe NR, et al. Why don't physicians follow clinical practice guidelines? A framework for improvement. JAMA 1999; 282: 1458-1465.

33 Légaré F. Assessing barriers and facilitators to knowledge use. In: Straus SE, Tetroe J, Graham ID. eds. Knowledge Translation in Health care: Moving from Evidence to Practice. Oxford, WileyBlackwell, 2009; pp. 83-93.

34 Cochrane Effective Practice and Organisation of Care Group. EPOC Register of Studies. http:/ / epoc.cochrane.org/epoc-registerstudies Date last accessed: February 23, 2012.

35 Cabana MD, Coffman JM. Recent developments in asthma education. Curr Opin Allergy Clin Immunol 2011; 2: 132-136.

36 Renzi PM, Ghezzo H, Goulet S, et al. Paper stamp checklist tool enhances asthma guidelines knowledge and implementation by primary care physicians. Can Respir J 2006; 13: 193-197.

37 Levy M, Parmar M, Coetzee D, et al. Respiratory consultations in asthmatic compared with non-asthmatic children in general practice. Br Med J (Clin Res Ed) 1985; 291: 29-30.

38 Levy M, Bell L. General practice audit of asthma in childhood. Br Med J (Clin Res Ed) 1984; 289: 1115-1116.

39 Speight AN, Lee DA, Hey EN. Underdiagnosis and undertreatment of asthma in childhood. Br Med J (Clin Res Ed) 1983; 286: 1253-1256.
40 Franco R, Santos AC, do Nascimento HF, et al. Cost-effectiveness analysis of a state funded programme for control of severe asthma. BMC Public Health 2007; 7: 82.

41 Alvarez GG, Schulzer M, Jung D, et al. A systematic review of risk factors associated with near-fatal and fatal asthma. Can Respir J 2005; 12: 265-270.

42 Towns SJ, van Asperen PP. Diagnosis and management of asthma in adolescents. Clin Respir J 2009; 3: 69-76.

43 Gibson PG, McDonald VM, Marks GB. Asthma in older adults. Lancet 2010; 376: 803-813.

44 Davis D, Davis N. Selecting educational interventions for knowledge translation. CMAJ 2010; 182: E89-E93.

45 Grimshaw JM, Shirran L, Thomas R, et al. Changing provider behavior: an overview of systematic reviews of interventions. Med Care 2001; 39: Suppl. 2, II2-II45.

46 Grimshaw J, Eccles M, Campbell M, et al. Cluster randomized trials of professional and organizational behavior change interventions in health care settings. Ann Am Acad Pol Soc Sci 2005; 599: 71-93.

47 Neville RG, Clark RC, Hoskins G, et al. National asthma attack audit 1991-2. General Practitioners in Asthma Group. BMJ 1993; 306: 559-562.

48 Bryce FP, Neville RG, Crombie IK, et al. Controlled trial of an audit facilitator in diagnosis and treatment of childhood asthma in general practice. BMJ 1995; 310: 838-842.

49 Hoskins G, Neville RG, Smith B. Evaluating asthma audit: experiences from practice. Asthma Gen Prac 1998; 6: 24-27.

50 Sheehan P. Intention-behavior relations: a conceptual and empirical review. Eur Rev Soc Psychol 2002; 12: 1-36.

51 Damiani G, Pinnarelli L, Colosimo SC, et al. The effectiveness of computerized clinical guidelines in the process of care: a systematic review. BMC Health Serv Res 2010; 10: 2.

52 Heselmans A, Van de Velde S, Donceel P, et al. Effectiveness of electronic guideline-based implementation systems in ambulatory care settings - a systematic review. Implement Sci 2009; 4: 82.

53 Landry R. Knowledge management and commercialization. In: Straus S, Tetroe J, Graham ID, eds. Knowledge Translation in Health Care: Moving from Evidence to Practice. Oxford, WileyBlackwell, 2009; pp. 280-290.

54 Global Initiative for Asthma. www.ginasthma.org.

55 Haahtela T, Klaukka T, Koskela K, et al. Asthma programme in Finland: a community problem needs community solutions. Thorax 2001; 56: 806-804.

56 Haahtela T, Tuomisto LE, Pietinalho A, et al. A 10 year asthma programme in Finland : major change for the better. Thorax 2006; 61: 663-670.

57 Haahtela T, von Hertzen L, Mäkelä M, et al. Finnish Allergy Programme 2008-2018: time to act and change the course. Allergy 2008; 63: 634-645.

58 Kupczyk M, Haahtela T, Cruz AA, et al. Reduction of asthma burden is possible through National Asthma Plans. Allergy 2010; 65: 415-419.

59 von Hertzen LC, Savolainen J, Hannuksela M, et al. Scientific rationale for the Finnish Allergy Programme 2008-2018: emphasis on prevention and endorsing tolerance. Allergy 2009; 64: 678-701.

60 Reissel E, Herse F, Väänänen J, et al. The price of asthma in Finland 1987-2005: costs and financial benefits of treating a chronic disease. Finn Med J 2010; 9: 811-816.

61 Souza-Machado C, Souza-Machado A, Franco R, et al. Rapid reduction in hospitalisations after an intervention to manage severe asthma. Eur Respir J 2010; 35: 515-521.

62 Franco R, Santos AC, Nascimento HF, et al. Cost-effectiveness analysis of a state funded programme for control of severe asthma. BMC Public Health 2007; 7: 82.

63 Franco R, Nascimento HF, Cruz AA, et al. The economic impact of severe asthma to low-income families. Allergy 2009; 64: 478-483. 
64 Andrade WC, Camargos P, Lasmar L, et al. A pediatric asthma management program in a low-income setting resulting in reduced use of health service for acute asthma. Allergy 2010; 65: 1472-1477.

65 English RG, Bateman ED, Zwarenstein MF, et al. Development of a South African integrated syndromic respiratory disease guideline for primary care. Prim Care Respir J 2008; 17: 156-163.

66 Fairall LR, Zwarenstein M, Bateman ED, et al. Effect of educational outreach to nurses on tuberculosis case detection and primary care of respiratory illness: pragmatic cluster randomised controlled trial. BMJ 2005; 331: 750-754.

67 Manning P, Greally P, Shanahan E. Asthma control and management: a patient's perspective. Ir Med J 2005; 98: 231-232.

68 FitzGerald JM, Quon B. The impact of asthma guidelines. Lancet 2010; 376: 751-753.
69 Poureslami I, Rootman I, Doyle-Waters MM, et al. Health literacy, language, and ethnicity-related factors in newcomer asthma patients to Canada: a qualitative study. J Immigr Minor Health 2011; 13: 315.

70 Boulet LP, Dorval E, Labrecque M, et al. Towards Excellence in Asthma Management: final report of an eight-year program aimed at reducing care gaps in asthma management in Quebec. Can Respir J 2008; 15: 302-310.

71 Aitt-Khaled N, Enarson DA, Bencharif N, et al. Implementation of asthma guidelines in health centres of several developing countries. Int J Tuberc Lung Dis 2006; 10: 104-109.

72 Latoszek-Berendsen A, Tange H, van den Herik HJ, et al. From clinical practice guidelines to computer-interpretable guidelines. A literature overview. Methods Inf Med 2010; 49: 550-570. 